\title{
Physioxia: a more effective approach for culturing human adipose-derived stem cells for cell transplantation
}

\author{
Chang Chen ${ }^{1,2,3 \dagger}$, Qi Tang ${ }^{1,2,3 \dagger}$, Yan Zhang ${ }^{1,2,3}$, Mei Yu ${ }^{1,2}$, Wei Jing ${ }^{1,2,3^{*}}$ and Weidong Tian ${ }^{1,2,3^{*}}$
}

\begin{abstract}
Background: Although typically cultured at an atmospheric oxygen concentration (20-21\%), adipose-derived stem cells (ASCs) reside under considerable low oxygen tension (physioxia) in vivo. In the present study, we explored whether and how physioxia could be a more effective strategy for culturing ASCs for transplantation.

Methods: After isolation, human ASCs were cultured under physioxia $\left(2 \% \mathrm{O}_{2}\right)$ and hyperoxia $\left(20 \% \mathrm{O}_{2}\right)$ until assayed. WST-8, Transwell, tube formation, $\beta$-galactosidase staining, and annexin V-FITC/PI assays were used to evaluate cell proliferation, migration, angiogenesis, senescence, and apoptosis, respectively. Survivability was determined by an ischemia model in vitro and nude mouse model in vivo, and the underlying metabolic alterations were investigated by fluorescence staining, flow cytometry, and real-time polymerase chain reaction.

Results: Compared with those in the hyperoxia group, cells in the physioxia group exhibited increased proliferation, migration, and angiogenesis, and decreased senescence and apoptosis. The increased survival rate of ASCs cultured in physioxia was found both in ischemia model in vitro and in vivo. The underlying metabolic reprogramming was also monitored and showed decreased mitochondrial mass, alkalized intracellular $\mathrm{pH}$, and increased glucose uptake and glycogen synthesis.
\end{abstract}

Conclusions: These results suggest that physioxia is a more effective environment in which to culture ASCs for transplantation owing to the maintenance of native bioactivities without injury by hyperoxia.

Keywords: Physioxia, Adipose-derived stem cells, Cell survival, Culture approach, Cell therapy

\section{Background}

Since first isolated in 1964 [1], human adipose-derived stem cells (ASCs) have garnered increasing attention [2]. Especially in the recent two decades, after the discovery of their stemness in 2001 [3], a growing body of research has indicated that ASCs possess properties of repair and regeneration, which include angiogenesis [4], multilineage differentiation [5], immunosuppression [6], and homing to ischemic tissues [7]. Consequently, there is great interest in and demand for utilizing ASCs in several clinical applications, such as osteoarthritis, heart

\footnotetext{
*Correspondence: jingwei@scu.edu.cn; drtwd@sina.com

Chang Chen and Qi Tang contributed equally to this work.

tEqual contributors

${ }^{1}$ State Key Laboratory of Oral Diseases, National Clinical Research Center for Oral Diseases, West China Hospital of Stomatology, Sichuan University,

Chengdu, People's Republic of China

Full list of author information is available at the end of the article
}

failure treatment and wound healing, according to the clinicaltrials.gov database.

However, there are still several problems to resolve, such as the donor choice [8], therapeutic safety [9], and standard protocol for expanding ASCs [10]; among these problems, the most suitable strategy for culturing and expanding ASCs in vitro has been continuously studied. Several factors should be considered, such as the culture medium, serum replacements, and seeding density [11]. However, there is an extremely appropriate standard to which can be referred, the stem cell niche, which is the surrounding microenvironment and intrinsic factors that control the self-renewal and differentiation of stem cells $[12,13]$.

A distinct difference between "standard culture conditions" and the ASC niche is the oxygen level [14]. Cell culture is typically performed at an atmospheric $\mathrm{O}_{2}$ concentration $(20-21 \%)$, i.e., the normoxia recognized by 
most researchers. However, there is a "mental shortcut" [15] neglecting the fact that the normoxia of $20-21 \% \mathrm{O}_{2}$ reflects the pathology of humans or animals, while the practical oxygen concentration of the ASC niche is lower, at $2 \%$ [16], which is called physioxia [17]. In other words, atmospheric normoxia represents a hyperoxic state for ASCs.

Many biological alterations occur when culturing such cells under hyperoxia (atmospheric normoxia), particularly with respect to metabolism [18], generating changes in cell proliferation [19] and differentiation [20], among others [21]. Underlying these discrepancies is the impact of hypoxia-inducible factor 1 (HIF-1), which is degraded at $\mathrm{O}_{2}$ levels over $5 \%$ [15].

By comparison, previous studies have commonly used physioxia at $2 \% \mathrm{O}_{2}$ to culture ASCs [22-24] as a transitory approach to increase the expansion and angiogenesis of ASCs rather than as a culture standard through the entire in vitro period, except for some studies [25-29]; yet, these studies did not examine the angiogenesis or survival of ASCs under an ischemic environment. Thus, the aim of the present study was to explore the superiority of physioxia $\left(2 \% \mathrm{O}_{2}\right)$ compared with hyperoxia $\left(20 \% \mathrm{O}_{2}\right)$ throughout the in vitro culture of ASCs by examining discrepancies in proliferation, migration, senescence, apoptosis, angiogenesis, and survivability, as well as the underlying mechanism.

\section{Methods}

\section{Cell isolation and culture}

Subcutaneous adipose tissue was collected from the abdomen of four healthy females (age, $25 \pm 5$ years, body mass index [BMI]: 19-22) after obtaining their consent. After washing with phosphate-buffered saline (PBS), the tissue was minced and digested with $0.2 \%$ collagenase (Sigma-Aldrich, St. Louis, MO, USA)/PBS for $40 \mathrm{~min}$ at $37^{\circ} \mathrm{C}$. The mixture was washed with PBS and centrifuged at $1000 \mathrm{rpm}$ for $5 \mathrm{~min}$, and the remaining pellet was cultured in $\alpha$-modified Eagle's medium ( $\alpha$-MEM; HyClone, GE Healthcare, Marlborough, MA, USA), 10\% fetal bovine serum (FBS; Gibco, San Jose, CA, USA), 100 IU penicillin, and $100 \mathrm{mg} / \mathrm{mL}$ streptomycin (Solarbio, Beijing, China). Cells in the physioxia group were cultured with $2 \% \mathrm{O}_{2}$ (using a modular chamber, Sanyo, Osaka, Japan) and 5\% $\mathrm{CO}_{2}$ at $37^{\circ} \mathrm{C}$ (physioxia ASCs, P-ASCs) until further analysis in the following tests at passage 3, with $20 \% \mathrm{O}_{2}$ and $5 \% \mathrm{CO}_{2}$ at $37^{\circ} \mathrm{C}$ as a control (hyperoxia ASCs, $\mathrm{H}$-ASCs). Cells from different donors were mixed at passage 2 to explore the general effect on ASCs.

\section{Cell characterization}

\section{Flow cytometric analysis}

Flow cytometry was used to analyze the surface markers of the ASCs. After detaching, $1 \times 10^{5}$ cells were incubated with PE- or FITC-conjugated antibodies against CD31, CD34, CD73, CD90, CD105, and HLA-DR for $30 \mathrm{~min}$ at $4{ }^{\circ} \mathrm{C}$. All antibodies were obtained from Abcam Biotechnology (Abcam, Cambridge, MA, USA). The cells were then analyzed using a BD Accurim ${ }^{\text {ma }}$ C6 flow cytometer (BD Biosciences, San Jose, CA, USA).

\section{Adipogenesis}

The cells were seeded onto six-well plates. After reaching $80 \%$ confluence, the culture medium was changed to $\alpha$-MEM supplemented with $10 \% \mathrm{FBS}, 1 \mathrm{mmol} / \mathrm{L}$ dexamethasone (Sigma-Aldrich, St. Louis, MO, USA), $10 \mathrm{mmol} / \mathrm{L}$ insulin (Sigma-Aldrich, St. Louis, MO, USA), $200 \mathrm{mmol} / \mathrm{L}$ indomethacin (Sigma-Aldrich, St. Louis, MO, USA) and $0.5 \mathrm{mmol} / \mathrm{L}$ 3-isobutyl-1-methylxanthine (IBMX; Sigma-Aldrich, St. Louis, MO, USA) for 7 days. Lipid clusters were stained with oil red $\mathrm{O}$.

\section{Western blotting}

Western blotting was performed as previously described [30], with slight modifications. After being dissolved in radioimmunoprecipitation assay (RIPA) buffer (KeyGEN, Nanjing, Jiangsu, China), $30 \mu \mathrm{g}$ of protein, as detected by bicinchoninic acid (BCA) assay, was separated on a $10 \%$ polyacrylamide gel and blotted onto a polyvinylidene fluoride (PVDF) membrane. The membrane was blocked with $5 \%$ skim milk and then treated with primary antibodies against HIF-1 (1:1000, 14,179, Cell Signaling Technology, Beverly, MA, USA) and $\beta$-actin (1:1000, ab3280, Abcam, Cambridge, MA, USA) overnight at $4{ }^{\circ} \mathrm{C}$, followed by $1 \mathrm{~h}$ of incubation with horseradish peroxidase (HRP)-conjugated secondary antibodies at room temperature. The signals were detected with Amersham ECL Select Western Blotting Detection Reagent (GE, Waukesha, WI, USA) according to the manufacturer's protocol. The signals were visualized using an ImageQuant LAS 4000 mini (GE, Waukesha, WI, USA).

\section{WST-8}

Cell Counting Kit 8 (WST-8; Dojindo, Kumamoto, Japan) was used to determine the proliferation of P-ASCs and H-ASCs. The cells $\left(1 \times 10^{3}\right)$ were seeded onto 96-well plates, and after 1, 2, 3, 4, 5, 6, and 7 days, the culture medium was replaced with $100 \mu \mathrm{L}$ of WST-8 dye solution $(90 \mu \mathrm{L}$ of $\alpha$-MEM with $10 \mu \mathrm{L}$ WST-8) for $2 \mathrm{~h}$ at $37^{\circ} \mathrm{C}$. Subsequently, the medium was discarded, and the absorbance at $450 \mathrm{~nm}$ was detected using a spectrophotometer (Multiskan GO, Thermo Fisher Scientific, Waltham, MA, USA).

\section{Cell doubling curve}

ASCs were seeded onto six-well plates at a concentration of $3 \times 10^{4}$ per well. The cells were collected at the 
indicated time points $(1,2,3,4,5,6$, and 7 days), and the cell numbers were measured using an Automated Cell Counter (Bio-Rad, Hercules, CA, USA).

\section{Determination of reactive oxygen species (ROS), mitochondrial mass, and glucose uptake}

The ROS level, mitochondrial mass and glucose uptake were determined by staining with $1 \mu \mathrm{M}$ dihydrodichlorofluorescein diacetate $\left(\mathrm{H}_{2} \mathrm{DCFDA}\right.$, Sigma-Aldrich, St. Louis, MO, USA), $10 \mathrm{nM}$ nonyl acridine orange (NAO, Sigma-Aldrich, St. Louis, MO, USA) and $150 \mu \mathrm{M}$ 2-[N-(7-nitrobenz-2-oxa-1,3-diazol-4-yl) amino]-2-deoxy-D-glucose (2-NBDG, Life Technologies, Gaithersburg, MD, USA), respectively, for $30 \mathrm{~min}$ at $37^{\circ} \mathrm{C}$. The results were acquired by fluorescence microscopy (Olympus, Hamburg, Germany) and BD Accuri ${ }^{\mathrm{Tm}}$ C6 (BD Biosciences, San Jose, CA, USA) with a minimum of 5000 events per sample. ROS inhibition was produced using $100 \mu \mathrm{M}$ butylated hydroxyanisole (BHA, Sigma-Aldrich, St. Louis, MO, USA).

\section{Transwell assay}

After incubation in serum-free medium for $24 \mathrm{~h}, 1 \times 10^{5}$ cells were transferred to the upper chamber of a Transwell (Corning, Corning, NY, USA). Medium containing $10 \%$ FBS was added to the lower chamber as a chemoattractant. After $24 \mathrm{~h}$, nonmigratory cells in the upper chamber were removed. The migrated cells were fixed with $4 \%$ paraformaldehyde for $30 \mathrm{~min}$, followed by $0.1 \%$ crystal violet (Sigma-Aldrich, St. Louis, MO, USA) staining for $15 \mathrm{~min}$. After images were captured, the crystal violet in the cells was extracted by $10 \%$ acetic acid for $15 \mathrm{~min}$, and the absorbance at $600 \mathrm{~nm}$ was measured using a spectrophotometer (Multiskan GO, Thermo Fisher Scientific, Waltham, MA, USA).

\section{Cell senescence}

We assayed the ASCs for senescence-associated $\beta$-galactosidase (SA- $\beta$-Gal) activity using a Senescence $\beta$-Galactosidase Staining Kit (Beyotime, Shanghai, China) according to the manufacturer's instructions. The SA- $\beta-\mathrm{Gal}^{+}$area was calculated by ImageJ (NIH, Bethesda, MD, USA) using the ratio of Periodic acid-Schiff $(\mathrm{PAS})^{+}$area to the total area of the image.

\section{Cell apoptosis}

ASC apoptosis was measured using an Annexin V-FITC/ PI Apoptosis Detection Kit (KeyGEN, Nanjing, Jiangsu, China) according to the manufacturer's instructions. Flow cytometry was conducted using the BD Accuri ${ }^{\mathrm{Tm}}$ C6 flow cytometer (BD Biosciences, San Jose, CA, USA).

\section{Tube formation assay}

ASCs $\left(2 \times 10^{5}\right)$ were seeded onto 96-well plates coated with Matrigel (Corning, Corning, NY, USA). After incubation at $37^{\circ} \mathrm{C}$ for $6 \mathrm{~h}$, the cells were imaged under a microscope (Olympus, Hamburg, Germany). The images were quantified using ImageJ (NIH, Bethesda, MD, USA).

Table 1 Primer sequences

\begin{tabular}{|c|c|c|}
\hline Gene & Forward (5' to $\left.3^{\prime}\right)$ & Reverse $\left(5^{\prime}\right.$ to $\left.3^{\prime}\right)$ \\
\hline HPRT & CCTGACCAAGGAAAGCAAAG & GACCAGTCAACAGGGGACAT \\
\hline VEGF & AGGGAAGAGGAGGAGATGAG & GCTGGGTTTGTCGGTGTT \\
\hline VEGFR2 & CTGGCTACTTCTTGTCATCATCCTACG & TGGCATCATAAGGCAGTCGTTCAC \\
\hline VWF & ACCTTGGTCACATCTTCACATTCACTC & AAGTCATTGGCTCCGTTCTCATCAC \\
\hline BNIP3 & AGGGCTCCTGGGTAGAACTG & ACTCCGTCCAGACTCATGCT \\
\hline COX4I1 & GCCATGTTCTTCATCGGTTT & CATCCTCTTGGTCTGCTTGG \\
\hline $\operatorname{COX} 412$ & CCCTACACCAACTGCTATGC & СТTСССТТСТССТСТССТТ \\
\hline PDK1 & AATCACACAGACGCCTAGCA & CATCCTCTTGGTCTGCTTGG \\
\hline LDHA & ATCTTGACCTACGTGGCTTGGA & CCATACAGGCACACTGGAATCTC \\
\hline MCT4 & ATCTGCTTTGCCATCTTTGC & GTCCAGAAAGGACAGCCATC \\
\hline NHE2 & TTCATGCCACGGATAAATGA & TTCTCTTCAGGCCAGCAAAT \\
\hline NHE3 & AGGTCCATGTCAACGAGGTC & ACTATGCCCTTCACGCAGTC \\
\hline CAR9 & GTCTCGCTTGGAAGAAATCG & ACAGGGCGGTGTAGTCAGAG \\
\hline GLUT1 & CATAGCCACCTCCTGGGATA & AATCACACAGACGCCTAGCA \\
\hline GLUT3 & GCACATAGCTATCAAGTGTGC & AGTGAGAAATGGGACCCTGC \\
\hline PGM & TGGAAATACGGAATGCTGAA & GCTGCCTTTGATGGAGATG \\
\hline GYS1 & ACCCACCTTGTTAGCCACCT & AACCGCACTTTGTCCATGTC \\
\hline PYGL & CCAAAGCAGCCACATCATC & GCCCTAACTATCGGGACCAT \\
\hline
\end{tabular}


Real-time polymerase chain reaction (RT-PCR)

RNA was extracted using RNAiso Plus (TaKaRa Biotechnology, Dalian, Liaoning, China) according to the manufacturer's instructions, followed by cDNA synthesis using a First Strand cDNA Synthesis Kit (Thermo Fisher Scientific, Waltham, MA, USA). Quantitative RT-PCR was performed using the Eco Real-Time PCR System (Illumina, San Diego, CA, USA) and SYBR Premix Ex Taq (TaKaRa Biotechnology, Dalian, Liaoning, China) with the following conditions: 2 min at $95{ }^{\circ} \mathrm{C}$, followed by 40 cycles of $5 \mathrm{~s}$ at $95^{\circ} \mathrm{C}$ and $30 \mathrm{~s}$ at $60^{\circ} \mathrm{C}$. The relative expression levels were calculated by the $2^{-\Delta \Delta c t}$ method and normalized to the housekeeping gene HPRT. The primer sequences are displayed in Table 1.

\section{Cell survival}

The survival assay was conducted as previously described [31]. Briefly, four harsh conditions (ischemic $\left[1 \% \mathrm{O}_{2}\right.$,
$\mathrm{pH} 6.4$ and $0.56 \mu \mathrm{M}$ glucose], hypoxic [ $1 \% \mathrm{O}_{2}, \mathrm{pH} 7.4$ and $5.6 \mu \mathrm{M}$ glucose], acidic $\left[20 \% \mathrm{O}_{2}, \mathrm{pH} 6.4\right.$ and $5.6 \mu \mathrm{M}$ glucose], and nutrient-depleted $\left[20 \% \mathrm{O}_{2}, \mathrm{pH} 7.4\right.$ and $0.56 \mu \mathrm{M}$ glucose] environments) were generated using a modular chamber (Sanyo, Osaka, Japan) and $\mathrm{N}$-2-hydroxyethylpiperazine- $\mathrm{N}^{\prime}$-2-ethanesulphonic acid-buffered Tyrode's solution. After incubating the ASCs for $24 \mathrm{~h}$ on 96 -well plates $\left(1 \times 10^{4}\right.$ per well), live/dead staining and WST-8 were applied to determine the survival of the P-ASCs and H-ASCs.

\section{Intracellular $\mathrm{pH}$ detection}

ASCs $\left(1 \times 10^{4}\right)$ on 96-well plates were stained with $5 \mu \mathrm{M}$ 2',7'-bis-(2-carboxyethyl)-5-(and-6)-carboxyfluorescein, acetoxymethyl ester (BCECF-AM, Millipore, Billerica, MA, USA) for $30 \mathrm{~min}$ at $37{ }^{\circ} \mathrm{C}$. A Multimode Reader (Thermo Fisher Scientific, Waltham, MA, USA) was

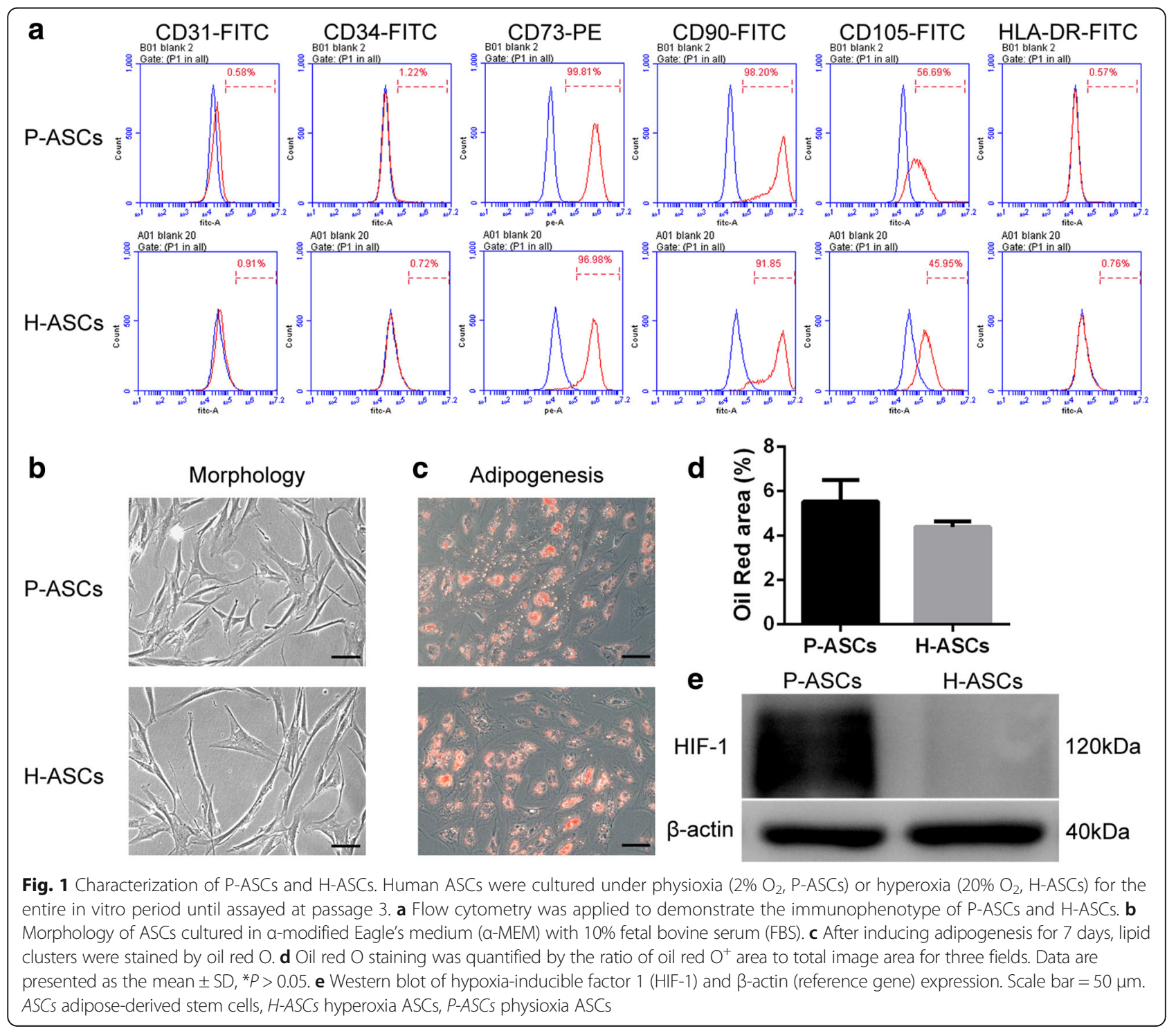


employed to measure the intracellular $\mathrm{pH}$ at excitation and emission wavelengths of $500 \mathrm{~nm}$ and $530 \mathrm{~nm}$, respectively. A calibration curve was produced by dyeing ASCs with $5 \mu \mathrm{M}$ BCECF-AM for $30 \mathrm{~min}$, with subsequent application of an Intracellular $\mathrm{pH}$ Calibration Buffer Kit (Thermo Fisher Scientific, Waltham, MA, USA) under different $\mathrm{pH}$ values $(4.5,5.5,6.5$, and 7.5$)$ in the presence of $10 \mu \mathrm{M} \mathrm{K} \mathrm{K}^{+} / \mathrm{H}^{+}$ionophore nigericin (Thermo Fisher Scientific, Waltham, MA, USA).

\section{PAS staining}

We used PAS staining to explore the different expression levels of glycogen in P-ASCs and H-ASCs. Cells on six-well plates were fixed with $4 \%$ paraformaldehyde and incubation for $5 \mathrm{~min}$ with $0.5 \%$ periodic acid (Solarbio, Beijing, China), followed by Schiff's reagent for $15 \mathrm{~min}$. After the cells were imaged, the $\mathrm{PAS}^{+}$area was quantified by Image $(\mathrm{NIH}$, Bethesda, MD, USA). a

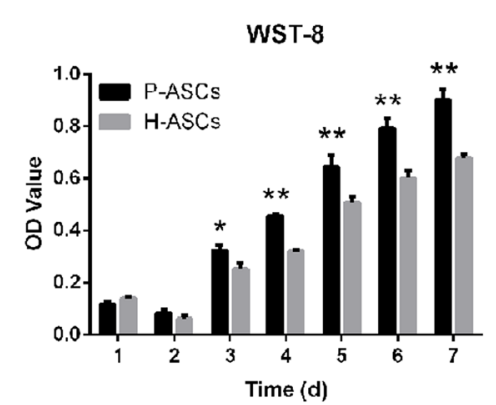

C

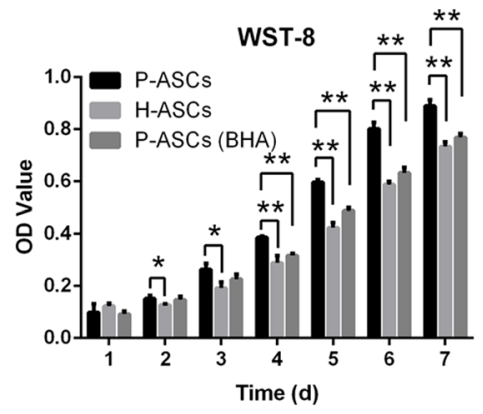

Cell Doubling Curve

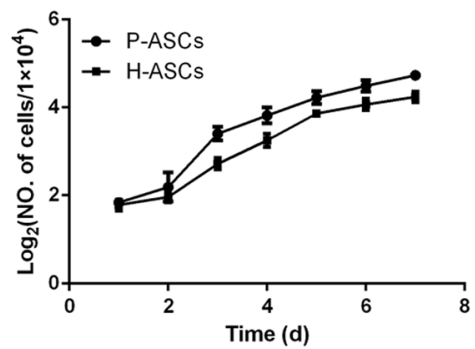

Cell Doubling Curve

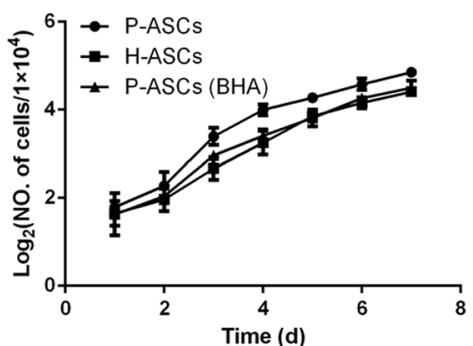

b

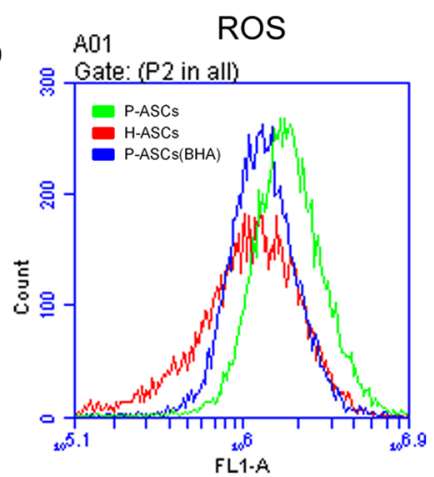

d

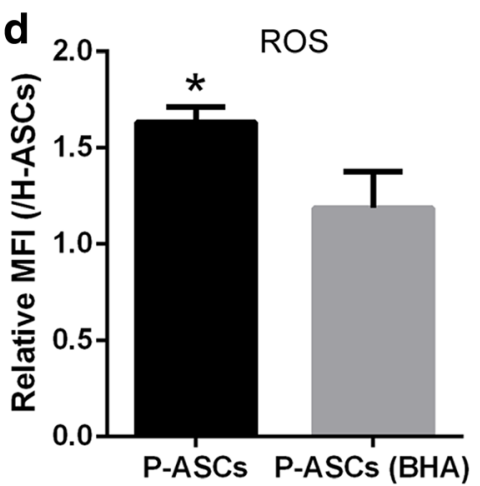

e

e P-ASCs

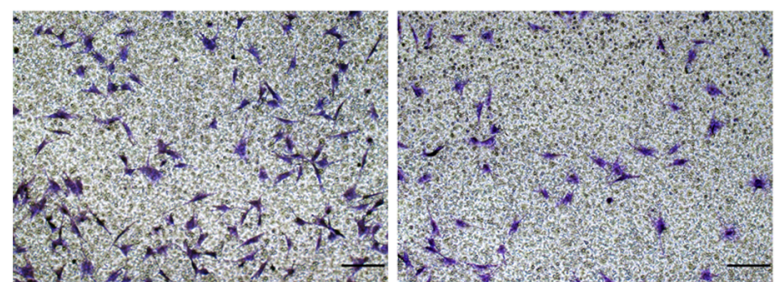

Transwell assay

H-ASCs

P-ASCs (BHA)

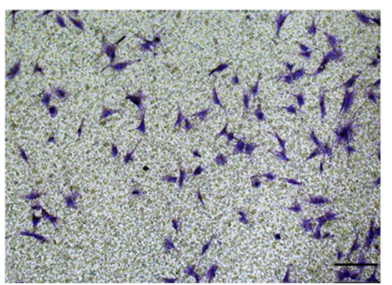

f OD value of migrated cells

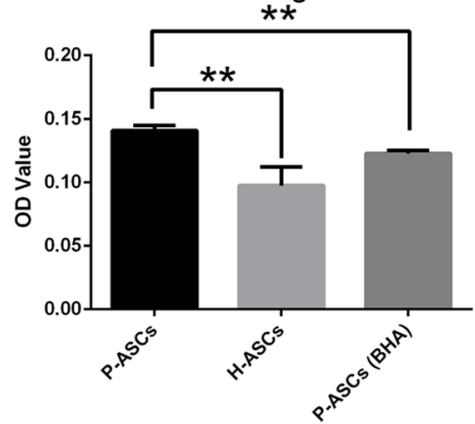

Fig. 2 Physioxia enhanced ASC proliferation and migration through ROS upregulation. a The proliferation of P-ASCs and H-ASCS measured by WST-8 and cell doubling curves. $\mathbf{b}$ and $\mathbf{d}$ P-ASCs were treated with $100 \mu \mathrm{M}$ BHA to inhibit ROS, as detected by flow cytometry. The relative MFI was quantified by the ratio of the MFI for P-ASCs and P-ASCs (BHA) to that of H-ASCS. $\mathbf{c}$ The proliferation of P-ASCs, H-ASCs and P-ASCs (BHA) measured by WST-8 and cell doubling curves. e Transwell assays were used for determining cell migration, and the migrated cells were stained by $0.1 \%$ crystal violet. $\mathbf{f}$ The crystal violet in migrated cells was extracted by $10 \%$ acetic acid, and the optical density values were determined. The cell doubling curve was produced by dividing the cell number by $10^{4}$ and then transforming the values to $\log _{2}$. Data are presented as the mean $\pm \mathrm{SD},{ }^{*} P<0.05,{ }^{*} P<0.01$, Student's $t$ tests, scale bar $=100 \mu \mathrm{m}$. ASCs adipose-derived stem cells, BHA butylated hydroxyanisole, H-ASCs hyperoxia ASCS, MFI mean fluorescence intensity, P-ASCs physioxia ASCS, ROS reactive oxygen species 


\section{Extracellular lactate assay}

The lactate content of the culture medium was measured using a Lactate Assay Kit (KeyGEN, Nanjing, Jiangsu, China) according to the manufacturer's protocol.

\section{In vivo experiment}

Fibrin gel and TdT-mediated dUTP-biotin nick end labeling (TUNEL) assays were conducted as previously described [31]. The fibrin gel was composed of $25 \mathrm{mg} / \mathrm{mL}$ fibrinogen, $20 \mathrm{mM} \mathrm{CaCl}_{2}$, and $2.5 \mathrm{U} / \mathrm{mL}$ thrombin. The cells $\left(1 \times 10^{6}\right)$ were mixed with $80 \mu \mathrm{L}$ of fibrin gel and subcutaneously transplanted into the dorsum of nude mice under deep anesthesia. After 24, 48 and $72 \mathrm{~h}$, the constructs were removed and immediately fixed with $4 \%$ paraformaldehyde for paraffin embedding. Subsequently, 5 - $\mu \mathrm{m}$-thick sections were cut and subjected to TUNEL assay using an In Situ Cell Death Detection Kit (KeyGEN, Nanjing, Jiangsu, China) to measure the ASC death. The number of $\mathrm{TUNEL}^{+}$cells was analyzed using Image-Pro Plus. Animal studies were conducted according to the protocol approved by the Ethics Committee of the State Key Laboratory of Oral Diseases, West China School of Stomatology, Sichuan University, China.

\section{Statistics}

Data were analyzed with GraphPad Prism 5.02 (GraphPad Software, San Diego, CA, USA) and are expressed as the mean \pm standard deviation. Unpaired Student's $t$ tests were performed, and statistical significance was considered at $P<0.05$. At least three replicates were analyzed in each experiment.

\section{Results}

\section{Identification of P-ASCs and H-ASCs}

Flow cytometric analysis indicated that the P-ASCs (physioxia ASCs) and $\mathrm{H}$-ASCs (hyperoxia ASCs) were positive for CD73, CD90, and CD105 and negative for CD31, CD34, and HLA-DR (Fig. 1a). Both the P-ASCs and H-ASCs exhibited a typical spindle-shaped morphology (Fig. 1b) and adipogenic ability (Fig. 1c and d). Compared with the H-ASCs, the P-ASCs exhibited upregulated HIF-1 protein expression, as determined by Western blotting (Fig. 1e).

\section{Physioxia enhanced ASC proliferation and migration through ROS upregulation}

Using WST-8 and cell doubling curves, P-ASCs exhibited increased proliferation (Fig. 2a) accompanied by an increased ROS level (Fig. $2 b$ and d). After ROS

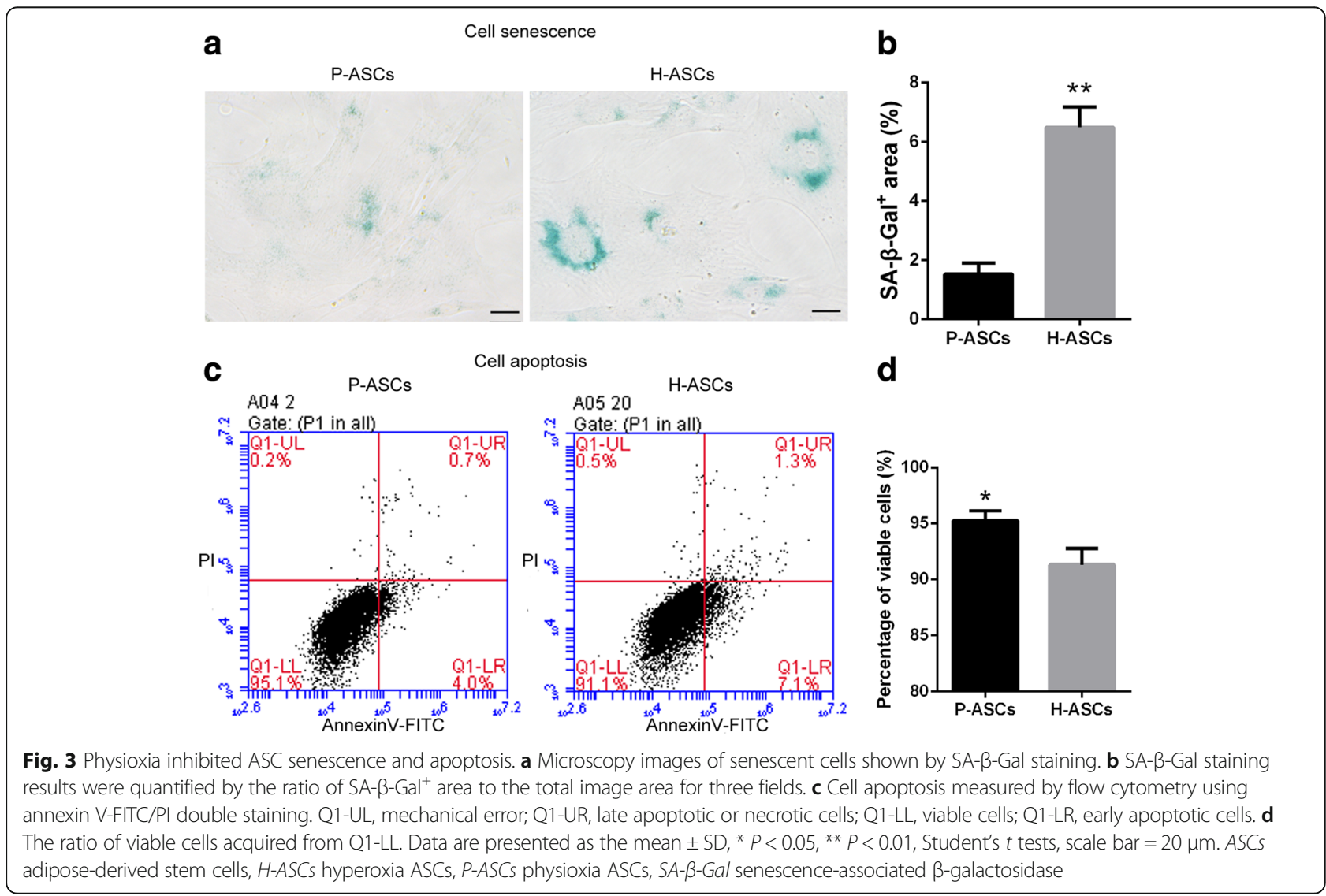


inhibition in P-ASCs by BHA (Fig. 2b, d), the enhanced P-ASC proliferation was decreased (Fig. 2c). Similarly, the Transwell assay (Fig. 2e, f) revealed reduced migration in H-ASCs and P-ASCs (BHA).

\section{Physioxia inhibited ASC senescence and apoptosis}

SA- $\beta-$ Gal staining revealed that physioxia inhibited ASC senescence (Fig. 3a), with a significant difference in the SA $-\beta-\mathrm{Gal}^{+}$area $(1.53 \pm 0.22 \%$ vs. $6.50 \pm 0.40 \%, P<0.01$, Fig. $3 b)$. Cell viability was significantly increased under physioxia compared with hyperoxia $(95.27 \pm 0.50 \%$ vs. $91.33 \pm 0.85 \%, P<0.05$, Fig. 3 c, d).

\section{Angiogenic activities of ASCs were promoted under physioxia}

Tube formation induced by Matrigel was employed to examine the angiogenic activities of the cells. The P-ASCs generated more meshes than the H-ASCs (Fig. 4a), and statistical analysis revealed significantly increased total mesh (Fig. 4b), branching length (Fig. 4c) and junction (Fig. 4d) values for P-ASCs than for H-ASCs (2.20-, 1.29-, and 1.41-fold greater, respectively). RT-PCR showed increased expression of the angiogenic genes vascular endothelial growth factor (VEGF), vascular endothelial growth factor receptor 2 (VEGF-R2) and von Willebrand factor (vWF) (Fig. 4e) in P-ASCs.

\section{Survival of P-ASCs was strengthened under ischemic} condition

After incubation in an ischemic environment (Fig. 5a) for $24 \mathrm{~h}, \mathrm{P}$-ASCs showed increased survival (Fig. 5B) and decreased death rates (Fig. 5A). A minor but significant difference was also detected under the hypoxic (Fig. 5b), acidic (Fig. 5c), and nutrient-depleted conditions (Fig. 5d).

\section{Variations in mitochondrial and $\mathrm{pH}$ metabolism of ASCs under physioxia}

By NAO staining, we measured a $43 \%$ decrease in the mitochondrial mass of P-ASCs (Fig. 6a, b), and the extracellular lactate concentration was much higher compared with that of H-ASCs $(7.07 \pm 0.54$ vs. $4.60 \pm 0.16$, $P<0.05$, Fig. 6d). Underlying these changes was the apparently upregulated mRNA expression of BCL2/adenovirus E1B $19 \mathrm{kDa}$ protein-interacting protein 3 (BNIP3), cytochrome c oxidase subunit 4 isoform 2 (COX4I2), pyruvate dehydrogenase kinase 1 (PDK1) and lactate dehydrogenase A (LDHA), as detected by RT-PCR (Fig. 6c).

Cells were treated under acidic conditions $(\mathrm{pH}$ 6.4) for $24 \mathrm{~h}$, and distinct alkalization in $\mathrm{H}$-ASCs was determined by intracellular $\mathrm{pH}$ detection $(7.48 \pm 0.15$ vs. 6.61 $\pm 0.17, P<0.05$, Fig. 6e). Additionally, the transcript levels of sodium-hydrogen exchangers (NHE2 and
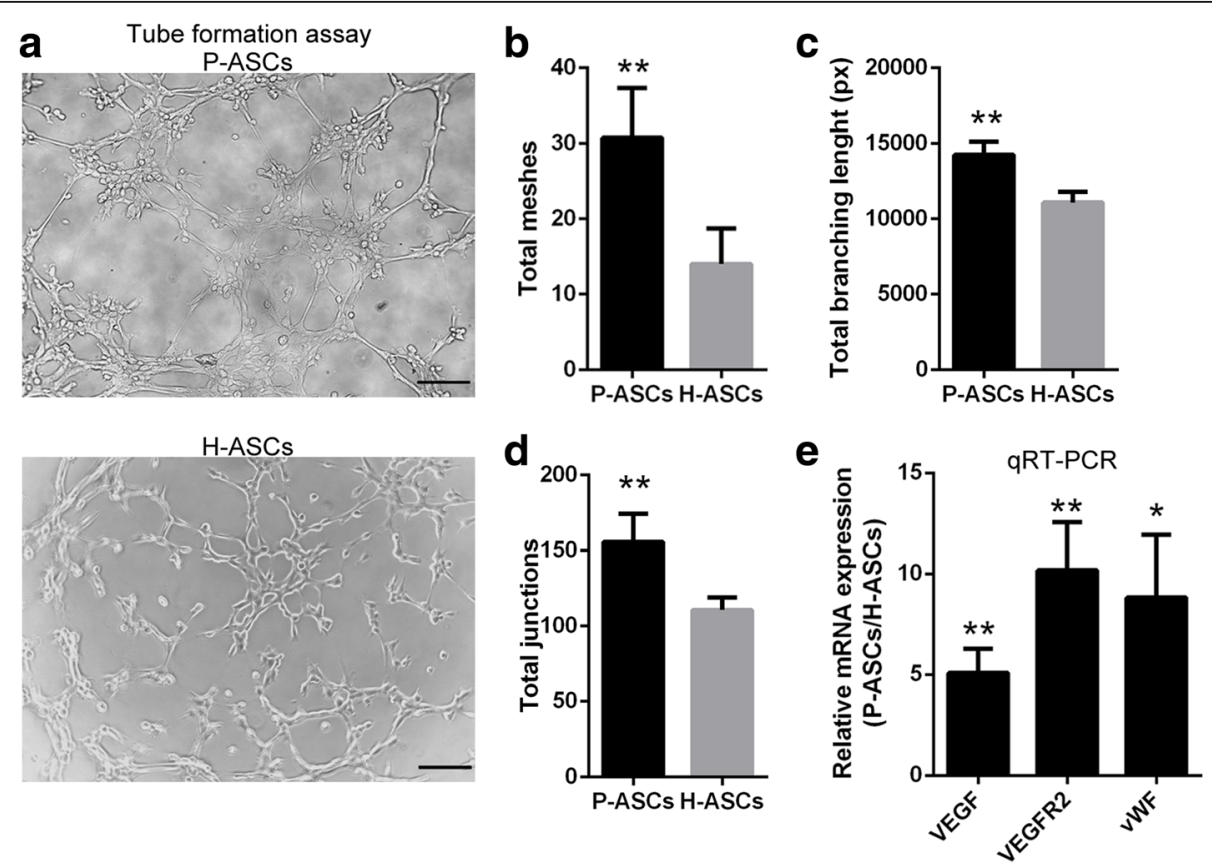

Fig. 4 Physioxia promoted angiogenic ability of ASCs. ASCs $\left(2 \times 10^{4}\right)$ were seeded onto 96-well plates coated with $50 \mu \mathrm{L}$ of Matrigel and cultured for $6 \mathrm{~h}$. a Mesh-like structures resulting from tube formation assay. b, $\mathbf{c}$ and $\mathbf{d}$ Total mesh, branching length, and junction values per field of view were quantified by ImageJ. Five fields were quantified. e Expression levels of mRNA encoding VEGF, VEGFR2, and vWF as measured by qRT-PCR. Data are presented as the mean $\pm S D$, ${ }^{*} P<0.05$ (P-ASCs/H-ASCs), ${ }^{*} P<0.01$ (P-ASCs/H-ASCs), Student's $t$ tests, $n=3$, scale bar $=100 \mu m$. ASCs adipose-derived stem cells, H-ASCS hyperoxia ASCS, P-ASCs physioxia ASCs, QRT-PCR quantitative real-time polymerase chain reaction, VEGF vascular endothelial growth factor, VEGFR2 vascular endothelial growth factor receptor 2, vWF von Willebrand factor 


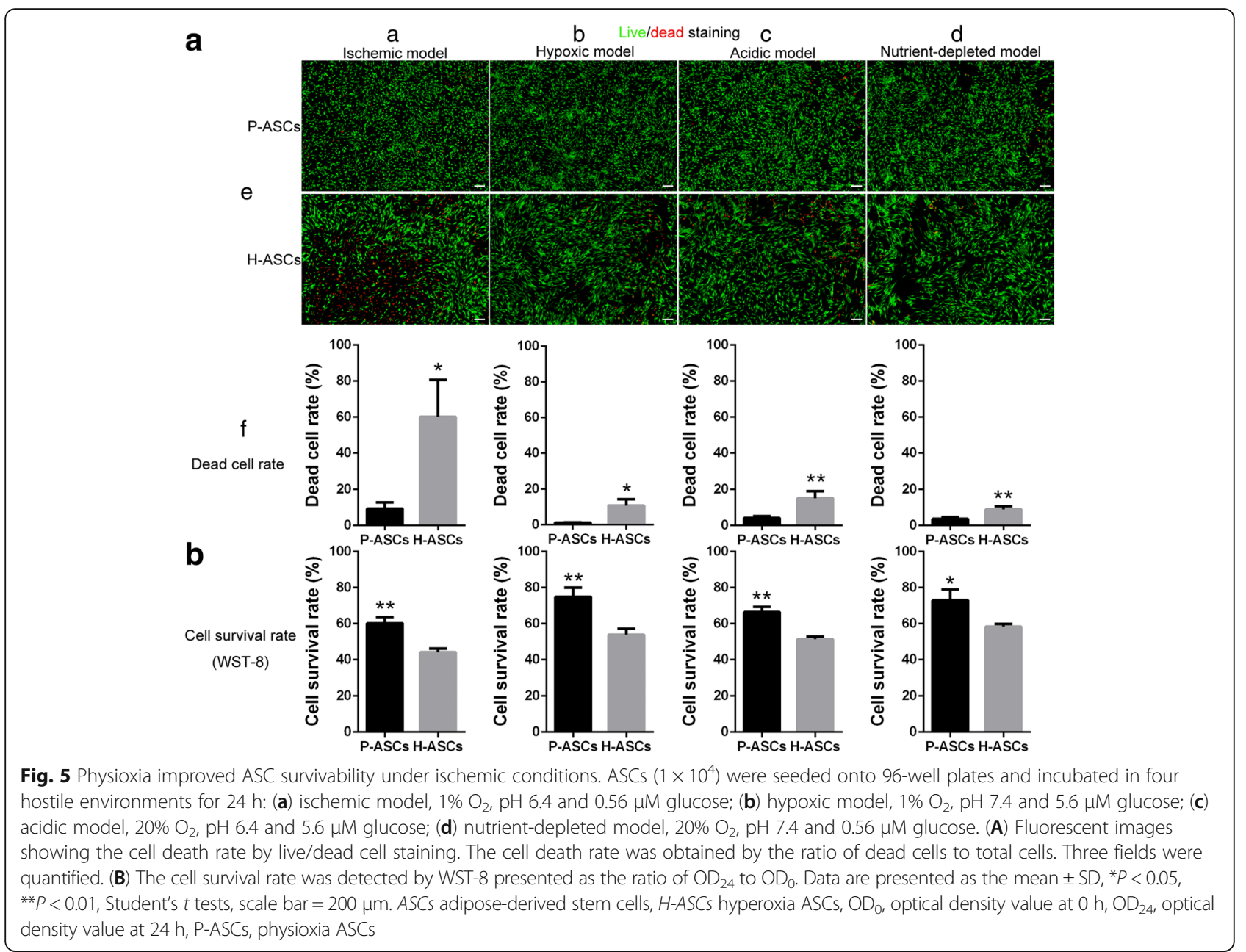

NHE3), carbonic anhydrase 9 (CAR9) and monocarboxylate transporter 4 (MCT4) were increased.

\section{Ascending glucose uptake and reserve in P-ASCs}

P-ASCs showed significantly increased glucose uptake, as measured by 2NBDG staining (1.20-fold greater, Fig. 7a, b), along with augmented mRNA levels of glucose transporters (GLUT1 and GLUT3), as demonstrated by RT-PCR (Fig. 7d). Increased glycogen reserves were found in P-ASCs, as detected by PAS staining (Fig. 7c), and the expression of glycogen synthesis (phosphoglucomutase [PGM] and glycogen synthase 1 [GYS1]) and breakdown genes (liver isoform of glycogen phosphorylase [PYGL]) were also upregulated (Fig. 7d).

\section{Increased survivability of P-ASCs in vivo}

The number of dead cells 24, 48, and $72 \mathrm{~h}$ after implantation with fibrin gel was detected by TUNEL assay (Fig. 8a); compared to H-ASCs $(47.46 \pm 8.58 \%, 57.35 \pm 7.41 \%$ and $63.70 \pm 3.32 \%)$, P-ASCs $(18.04 \pm 3.13 \%, 27.56 \pm 2.20 \%$ and $27.62 \pm 5.13 \%)$ showed a significantly lower death rate (Fig. 8b).

\section{Discussion}

Offering safe and effective cell therapy products for clinical applications is consistent with good manufacturing practice (GMP) guidelines, which should be followed during the entire process of isolating, expanding and transplanting ASCs [32]. The present study compared ASCs cultured under hyperoxia $\left(20 \% \mathrm{O}_{2}\right)$ and physioxia $\left(2 \% \mathrm{O}_{2}\right.$, oxygen concentration in situ) and provides compelling evidence that the latter could be a more effective approach owing to the advantages of retaining cell proliferation, migration, survival in ischemia and angiogenesis, and suppressing senescence and apoptosis.

There are no differences between P-ASCs and H-ASCs in terms of immunophenotype, morphology or adipogenesis, and a previous study [25] revealed that culturing ASCs under physioxia does not increase the risk of tumourigenesis associated with ASCs, indicating that P-ASCs are safe for clinical therapy. Physioxia promoted cell proliferation and migration, and many studies have attributed this effect to the stabilization of HIF-1 in the lack of $\mathrm{O}_{2}[33,34]$. However, the ROS level was also increased in P-ASCs, suggesting that transient physioxia 

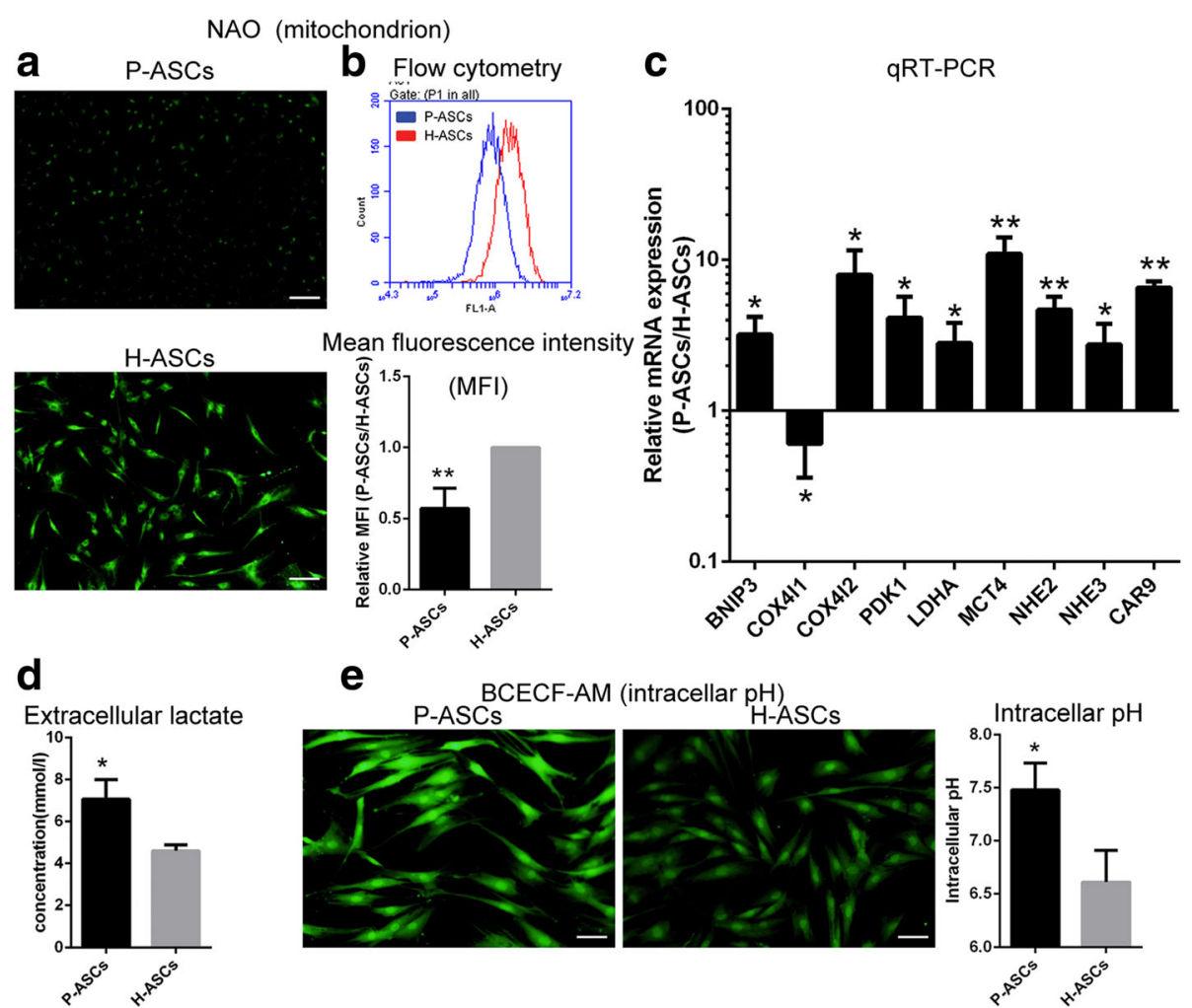

Mean fluorescence intensity
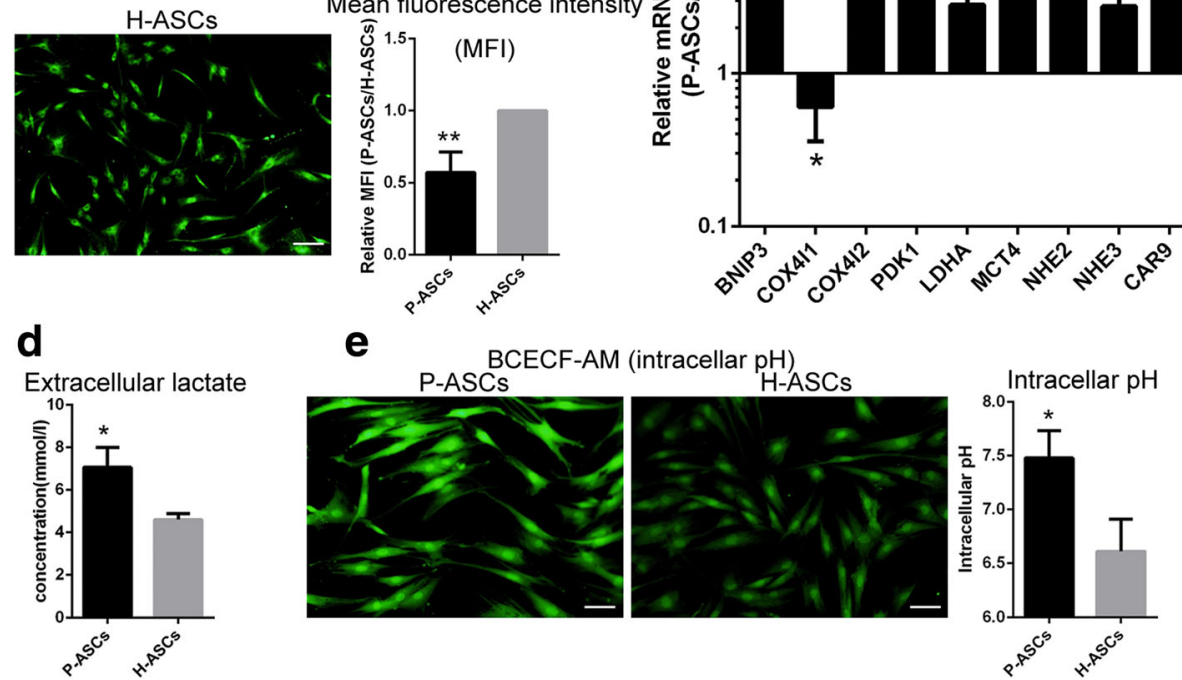

Fig. 6 Variations in mitochondrial and pH metabolism of P-ASCs. a and $\mathbf{b}$ Fluorescent images and flow cytometry results of mitochondrial mass determined by staining ASCs with NAO; the relative MFI was determined as the MFI of P-ASCs versus that of H-ASCs. c Expression of HIF-1 target genes evaluated by qRT-PCR. $\mathbf{d}$ Extracellular lactate concentration of P-ASCs and H-ASCs. e Cells cultured in the acidic model for $24 \mathrm{~h}$ were stained with BCECF-AM to determine the intracellular $\mathrm{pH}$. Data are presented as the mean $\pm \mathrm{SD},{ }^{*} P<0.05$ (P-ASCS/H-ASCs), ${ }^{*} P<0.01$ (P-ASCs/H-ASCs), Student's $t$ tests, $n=3$, scale bar $=100 \mu \mathrm{m}$. ASCs adipose-derived stem cells, BCECF-AM 2,7'-bis-(2-carboxyethyl)-5-(and-6)-carboxyfluorescein, acetoxymethyl ester, BNIP3 BCL2/adenovirus E1B $19 \mathrm{kDa}$ protein-interacting protein 3, mitophagy regulator, COX4/1 cytochrome c oxidase subunit 4 isoform 2, metabolic enzyme, COX412 cytochrome c oxidase subunit 4 isoform 2, metabolic enzyme, H-ASCs hyperoxia ASCs, LDHA lactate dehydrogenase A, glycolysis, MCT4 monocarboxylate transporter 4, lactate discharge, NAO nonyl acridine orange, NHE2 sodium-hydrogen exchanger 2, $\mathrm{H}^{+}$discharge, NHE3 sodium-hydrogen exchanger $3, \mathrm{H}^{+}$discharge, P-ASCs physioxia ASCs, PDK1 pyruvate dehydrogenase kinase 1, inactivating pyruvate dehydrogenase

can restore proliferation and migration through the augmentation of ROS [35]. Furthermore, we showed that without the injury caused by hyperoxia, physioxia is an appropriate condition for maintaining ASC proliferation and migration.

The relationship between physioxia and ROS is complicated [36]. In principle, HIF-1 decreases the ROS level $[37,38]$, which should be lower in P-ASCs, but the results show the opposite effect. The underlying mechanism remains unknown, especially in stem cells.

Many studies have shown the ability of HIF-1 to enhance angiogenesis under transient physioxia [39, 40], but consistent with most studies on physioxia and ASCs, the cells were isolated from a physioxic niche and then cultured under atmospheric hyperoxia, which could injure the bioactivity of the cells. Thus, the discrepancy of such bioactivity between P-ASCs and $\mathrm{H}$-ASCs is not due to the acceleration of physioxia but reflects the damage caused by hyperoxia. Although transient physioxia preconditioning would be applied prior to transplantation for recovery, in the present method, culturing cells under physioxia through the entire in vitro period may be a better approach; however, further research is required.

To acquire an excellent stem cell product, cell viability should also be considered. Physioxia evidently suppressed senescence and apoptosis under nonstressful condition. The required survival of cells implanted in an ischemic environment composed of low oxygen, glucose, and $\mathrm{pH}$ levels is a main barrier for cell therapy [41]. Thus, we established an ischemic model and observed increased adaptability in P-ASCs; the same effect was observed in hypoxic, acidic, and nutrient-depleted environments, explaining the superiority of P-ASCs under these conditions and resulting in preferable adaptability in an ischemic environment.

The underlying mechanisms induced by HIF-1 and described in a previous study using an HIF-1 activator [31] were also observed in P-ASCs, but with an inverse trend in the ROS level. Briefly, more efficient 


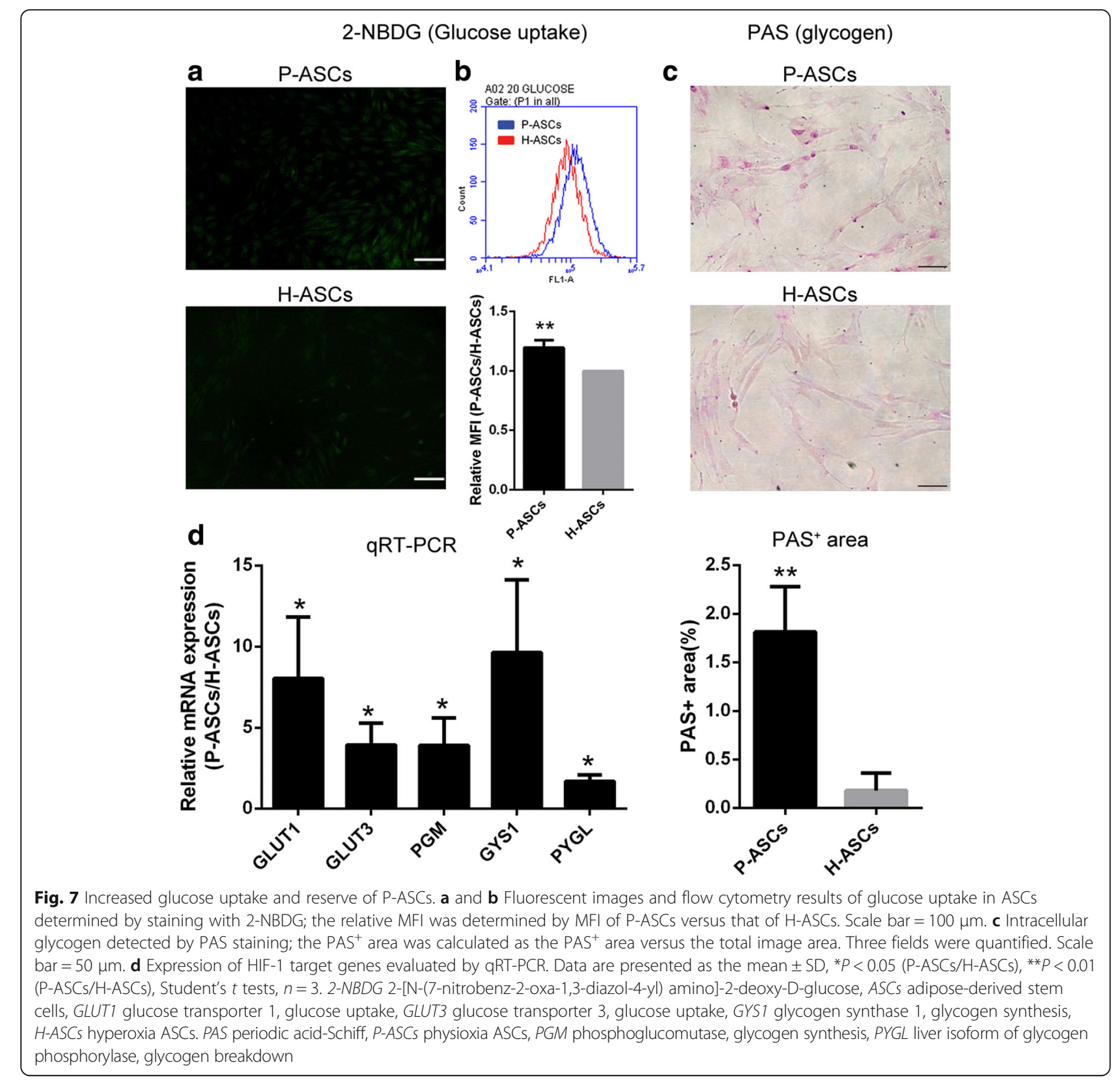

aerobic oxidation (switch of cytochrome c oxidase subunit COX4I1 to COX4I2) and a switch to glycolysis (declined mitochondrial mass (Fig. $6 \mathrm{a}$ and $\mathrm{b}$ ) caused by BNIP3 and increased glycolysis by PDK1 and LDHA) indicate adaptability to hypoxia (Fig. 5b). Additionally, enhanced glucose uptake (GLUT1 and GLUT3 (Fig. 7a and b)), glycogen synthesis (PGM and GYS1 (Fig. 7c)), and glycogen breakdown (PYGL) demonstrated cell adaptation to nutrient depletion (Fig. 5d), while an alkalescent intracellular pH (Fig. 6e) (CAR9, NHE2 and NHE3 [export $\mathrm{H}^{+}$] and MCT4 [export lactate] (Fig. 6d)) indicated adaptability to acidic conditions (Fig. 5c).
This study shows for the first time that culturing ASCs under physioxia for the entire in vitro term could induce metabolic alterations and improve ASC survival in ischemic environment. Our observations illustrate the molecular, cellular, and in vivo biological effects induced by physioxia in ASCs, presenting a significant mechanistic basis for culturing ASCs under physioxia for cell therapy. However, longer culture periods should be examined to guarantee the security of cell properties under this condition. Moreover, specific cell therapy models should be constructed to verify the ultimate efficacy of the cells, including when applied in adipose regeneration, heart failure treatment, and wound healing. 


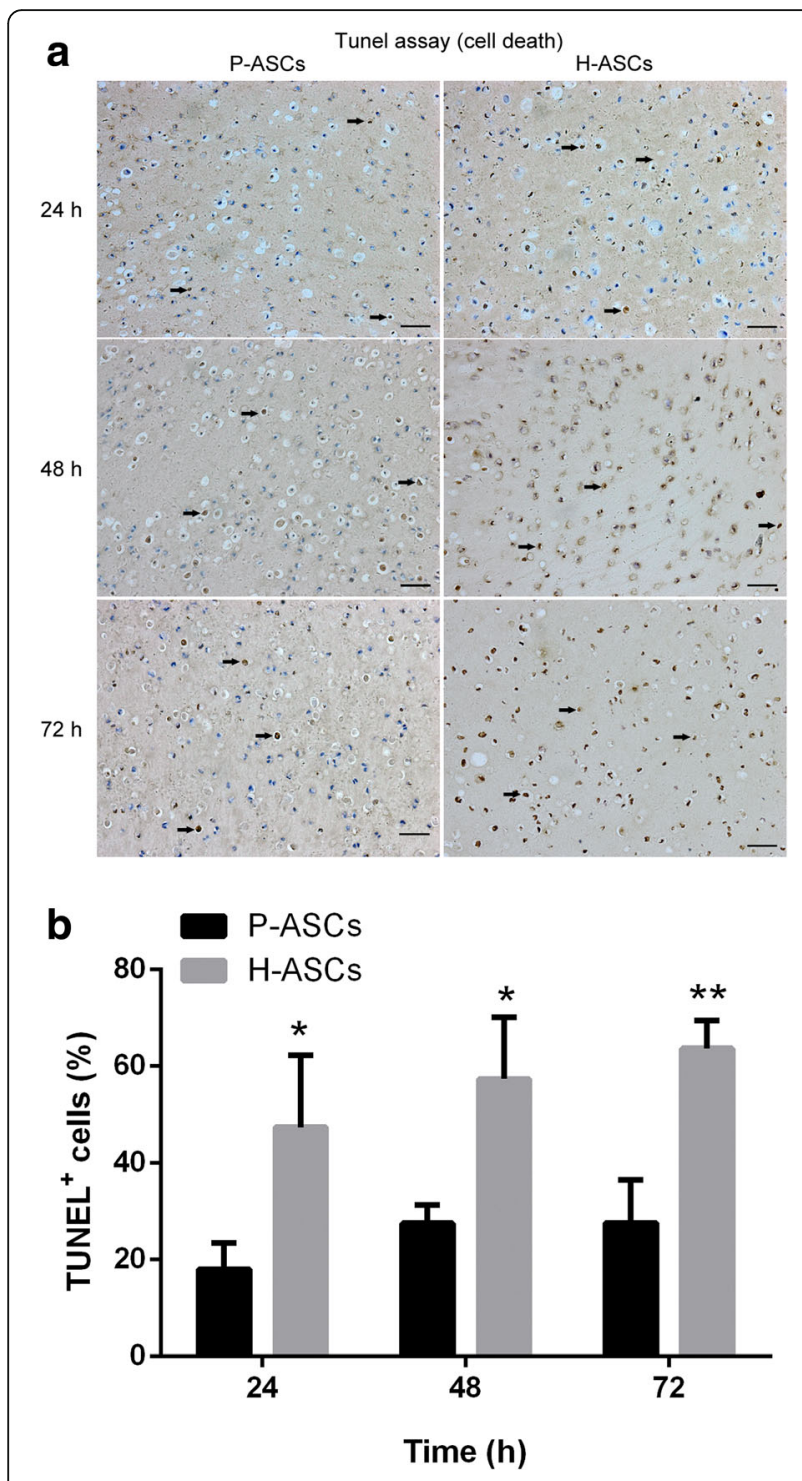

Fig. 8 Physioxia increased ASC survivability in vivo. After mixing with $80 \mu \mathrm{L}$ of fibrin gel, $1 \times 10^{6}$ P-ASCs or H-ASCs were subcutaneously transplanted into the dorsum of nude mice. The implants were extracted after 24,48 , and $72 \mathrm{~h}$. a TUNEL assay was used to stain the nucleus of dead cells. The black arrows indicate dead cells. $\mathbf{b}$ The TUNEL ${ }^{+}$cell rate was determined by the ratio of $\mathrm{TUNEL}^{+}$cells versus total cells. Three fields were quantified. Data are presented as the mean $\pm \mathrm{SD},{ }^{*} P<0.05$, ${ }^{*} P<0.01$, Student's $t$ tests, scale bar $=100 \mu \mathrm{m}$. ASCs adipose-derived stem cells, H-ASCS hyperoxia ASCS, P-ASCS physioxia ASCS, TUNEL TdTmediated dUTP-biotin nick end labeling

\section{Conclusions}

In summary, the present results suggest that culturing ASCs under physioxia $\left(2 \% \mathrm{O}_{2}\right)$ for the entire in vitro period, not under conventional hyperoxia $\left(20 \% \mathrm{O}_{2}\right)$, could be a more effective approach for cell therapy applications owing to the improvements in proliferation, migration, survival and angiogenesis, and suppression of senescence and apoptosis.

\section{Abbreviations}

2-NBDG: 2-[N-(7-nitrobenz-2-oxa-1,3-diazol-4-yl) amino]-2-deoxy-D-glucose; ASCs: Adipose-derived stem cells; BCECF-AM: 2',7'-bis-(2-carboxyethyl)-5-(and6)-carboxyfluorescein, acetoxymethyl ester; BHA: Butylated hydroxyanisole; BNIP3: BCL2/adenovirus E1B $19 \mathrm{kDa}$ protein-interacting protein 3; CAR9: Carbonic anhydrase 9; COX4I2: Cytochrome c oxidase subunit 4 isoform 2; FBS: Fetal bovine serum; GLUT1: Glucose transporter 1; GLUT3: Glucose transporter 3; GMP: Good manufacturing practice; GYS1: Glycogen synthase 1; $H_{2}$ DCFDA: Dihydrodichlorofluorescein diacetate; HIF-1: Hypoxia-inducible factor 1; HRP: Horseradish peroxidase; IBMX: 3-isobutyl-1-methylxanthine; LDHA: Lactate dehydrogenase A; MCT4: Monocarboxylate transporter 4; NAO: Nonyl acridine orange; NHE2: Sodium-hydrogen exchanger 2; NHE3: Sodium-hydrogen exchanger 3; PAS: Periodic acid-Schiff (PAS); PBS: Phosphate-buffered saline; PDK1: Pyruvate dehydrogenase kinase 1; PGM: Phosphoglucomutase; PVDF: Polyvinylidene fluoride; PYGL: Liver isoform of glycogen phosphorylase; RIPA: Radioimmunoprecipitation assay; ROS: Reactive oxygen species); RTPCR: Real-time polymerase chain reaction; SA- $\beta$-Gal: Senescence-associated $\beta$ galactosidase; TUNEL: TdT-mediated dUTP-biotin nick-end labeling; VEGF: Vascular endothelial growth factor; VEGF-R2: Vascular endothelial growth factor receptor 2; VWF: von Willebrand factor; WST-8: Cell Counting Kit 8

\section{Funding}

This study was supported by the National Natural Science Foundation of China (No. 81271119).

\section{Availability of data and materials}

All data generated or analyzed during this study are included in this published article.

\section{Authors' contributions}

CC, QT, WJ, and WT contributed to the study design, data collection, data analysis, and manuscript preparation. YZ and MY contributed to the data analysis. All authors have read and approved the final manuscript.

\section{Ethics approval and consent to participate}

Human adipose tissue was collected after consent was obtained. Animal studies were conducted according to the protocol approved by the Ethics Committee of the State Key Laboratory of Oral Diseases, West China School of Stomatology, Sichuan University, China.

\section{Competing interests}

The authors declare that they have no competing interests.

\section{Publisher's Note}

Springer Nature remains neutral with regard to jurisdictional claims in published maps and institutional affiliations.

\section{Author details}

${ }^{1}$ State Key Laboratory of Oral Diseases, National Clinical Research Center for Oral Diseases, West China Hospital of Stomatology, Sichuan University, Chengdu, People's Republic of China. ${ }^{2}$ National Engineering Laboratory for Oral Regenerative Medicine, West China Hospital of Stomatology, Sichuan University, Chengdu, People's Republic of China. ${ }^{3}$ Department of Oral and Maxillofacial Surgery, West China Hospital of Stomatology, Sichuan University, Chengdu, People's Republic of China.

Received: 15 January 2018 Revised: 18 April 2018 Accepted: 1 May 2018 Published online: 24 May 2018

\section{References}

1. Rodbell M. Metabolism of isolated fat cells. I. Effects of hormones on glucose metabolism and lipolysis. J Biol Chem. 1964;239:375-80.

2. Nordberg RC, Loboa EG. Our fat future: translating adipose stem cell therapy. Stem Cells Transl Med. 2015;4:974-9.

3. Zuk PA, Zhu M, Mizuno H, Huang J, Futrell JW, Katz AJ, et al. Multilineage cells from human adipose tissue: implications for cell-based therapies. Tissue Eng. 2001;7:211-28.

4. Kachgal S, Putnam AJ. Mesenchymal stem cells from adipose and bone marrow promote angiogenesis via distinct cytokine and protease expression mechanisms. Angiogenesis. 2011;14:47-59. 
5. Zuk PA, Zhu M, Ashiian P, De Ugarte DA, Huang Jl, Mizuno H, et al. Human adipose tissue is a source of multipotent stem cells. Mol Biol Cell. 2002;13: 4279-95.

6. Melief SM, Zwaginga JJ, Fibbe WE, Roelofs H. Adipose tissue-derived multipotent stromal cells have a higher immunomodulatory capacity than their bone marrow-derived counterparts. Stem Cells Transl Med. 2013;2:455-63.

7. Qin JB, Li KA, Li XX, Xie QS, Lin JY, Ye KC, et al. Long-term MRI tracking of dual-labeled adipose-derived stem cells homing into mouse carotid artery injury. Int J Nanomedicine. 2012;7:5191-203.

8. Varghese J, Griffin M, Mosahebi A, Butler P. Systematic review of patient factors affecting adipose stem cell viability and function: implications for regenerative therapy. Stem Cell Res Ther. 2017;8:45.

9. Toyserkani NM, Jorgensen MG, Tabatabaeifar S, Jensen CH, Sheikh SP Sorensen JA. Concise review: a safety assessment of adipose-derived cell therapy in clinical trials: a systematic review of reported adverse events. Stem Cells Transl Med. 2017;6:1786-94.

10. Arrizabalaga JH, Nollert MU. Properties of porcine adipose-derived stem cells and their applications in preclinical models. Adipocyte. 2017:6:217-23.

11. Riis S, Zachar V, Boucher S, Vemuri MC, Pennisi CP, Fink T. Critical steps in the isolation and expansion of adipose-derived stem cells for translational therapy. Expert Rev Mol Med. 2015;17:e11.

12. Naveiras O, Daley GQ. Stem cells and their niche: a matter of fate. Cell Mol Life Sci. 2006;63:760-6.

13. Spradling A, Drummond-Barbosa D, Kai T. Stem cells find their niche. Nature. 2001;414:98-104

14. Kim WS, Han J, Hwang SJ, Sung JH. An update on niche composition, signaling and functional regulation of the adipose-derived stem cells. Expert Opin Biol Ther. 2014;14:1091-102.

15. Ivanovic Z. Hypoxia or in situ normoxia: The stem cell paradigm. J Cell Physiol. 2009;219:271-5.

16. Mohyeldin A, Garzon-Muvdi T, Quinones-Hinojosa A. Oxygen in stem cell biology: a critical component of the stem cell niche. Cell Stem Cell. 2010;7 150-61

17. Anderson DE, Markway BD, Weekes KJ, HE MC, Johnstone B. Physioxia promotes the articular chondrocyte-like phenotype in human chondroprogenitor-derived self-organized tissue. Tissue Eng A. 2018:24:264-74

18. Prabhakar NR, Semenza GL. Oxygen sensing and homeostasis. Physiology (Bethesda). 2015:30:340-8.

19. Hubbi ME, Semenza GL. Regulation of cell proliferation by hypoxia-inducible factors. Am J Physiol Cell Physiol. 2015:309:C775-82.

20. Hawkins KE, Sharp TV, McKay TR. The role of hypoxia in stem cell potency and differentiation. Regen Med. 2013:8:771-82.

21. Buravkova LB, Andreeva ER, Gogvadze V, Zhivotovsky B. Mesenchymal stem cells and hypoxia: where are we? Mitochondrion. 2014;19 Pt A:105-12.

22. Fotia C, Massa A, Boriani F, Baldini N, Granchi D. Prolonged exposure to hypoxic milieu improves the osteogenic potential of adipose derived stem cells. J Cell Biochem. 2015;116:1442-53.

23. Qin HH, Filippi C, Sun S, Lehec S, Dhawan A, Hughes RD. Hypoxic preconditioning potentiates the trophic effects of mesenchymal stem cells on co-cultured human primary hepatocytes. Stem Cell Res Ther. 2015;6:237.

24. Yu Y, Zhou Y, Cheng T, Lu X, Yu K, Hong J, et al. Hypoxia enhances tenocyte differentiation of adipose-derived mesenchymal stem cells by inducing hypoxiainducible factor-1alpha in a co-culture system. Cell Prolif. 2016:49:173-84.

25. Choi JR, Pingguan-Murphy B, Wan Abas WA, Yong KW, Poon CT, Noor Azmi $M A$, et al. In situ normoxia enhances survival and proliferation rate of human adipose tissue-derived stromal cells without increasing the risk of tumourigenesis. PLoS One. 2015;10:e0115034.

26. Choi JR, Pingguan-Murphy B, Wan Abas WA, Noor Azmi MA, Omar SZ, Chua $\mathrm{KH}$, et al. Impact of low oxygen tension on stemness, proliferation and differentiation potential of human adipose-derived stem cells. Biochem Biophys Res Commun. 2014;448:218-24.

27. Wan Safwani WKZ, Choi JR, Yong KW, Ting I, Mat Adenan NA, PingguanMurphy B. Hypoxia enhances the viability, growth and chondrogenic potential of cryopreserved human adipose-derived stem cells. Cryobiology. 2017;75:91-9.

28. Yamamoto $Y$, Fujita M, Tanaka Y, Kojima I, Kanatani $Y$, Ishihara M, et al. Low oxygen tension enhances proliferation and maintains stemness of adipose tissue-derived stromal cells. BioResearch open access. 2013:2:199-205.

29. Fotia C, Massa A, Boriani F, Baldini N, Granchi D. Hypoxia enhances proliferation and stemness of human adipose-derived mesenchymal stem cells. Cytotechnology. 2015;67:1073-84.
30. Liu W, Zhou L, Zhou C, Zhang S, Jing J, Xie L, et al. GDF11 decreases bone mass by stimulating osteoclastogenesis and inhibiting osteoblast differentiation. Nat Commun. 2016;7:12794.

31. Chen C, Tang Q, Zhang Y, Dai M, Jiang Y, Wang H, et al. Metabolic reprogramming by HIF-1 activation enhances survivability of human adiposederived stem cells in ischaemic microenvironments. Cell Prolif. 2017:50

32. Giancola R, Bonfini T, lacone A. Cell therapy: cGMP facilities and manufacturing. Muscles Ligaments Tendons J. 2012;2:243-7.

33. Lee HJ, Ryu JM, Jung YH, Oh SY, Lee SJ, Han HJ. Novel pathway for hypoxiainduced proliferation and migration in human mesenchymal stem cells: involvement of HIF-1alpha, FASN, and mTORC1. Stem Cells. 2015:33:2182-95.

34. Kakudo N, Morimoto N, Ogawa T, Taketani S, Kusumoto K. Hypoxia enhances proliferation of human adipose-derived stem cells via HIF-1a activation. PLoS One. 2015;10:e0139890.

35. Kim JH, Park SH, Park SG, Choi JS, Xia Y, Sung JH. The pivotal role of reactive oxygen species generation in the hypoxia-induced stimulation of adiposederived stem cells. Stem Cells Dev. 2011;20:1753-61.

36. Gorlach A, Dimova EY, Petry A, Martinez-Ruiz A, Hernansanz-Agustin P, Rolo $A P$, et al. Reactive oxygen species, nutrition, hypoxia and diseases: Problems solved? Redox Biol. 2015:6:372-85.

37. Horak P, Crawford AR, Vadysirisack DD, Nash ZM, DeYoung MP, Sgroi D, et al. Negative feedback control of HIF-1 through REDD1-regulated ROS suppresses tumorigenesis. Proc Natl Acad Sci U S A. 2010;107:4675-80.

38. Semenza GL. Regulation of oxygen homeostasis by hypoxia-inducible factor 1. Physiology (Bethesda). 2009;24:97-106.

39. Fan L, Zhang C, Yu Z, Shi Z, Dang X, Wang K. Transplantation of hypoxia preconditioned bone marrow mesenchymal stem cells enhances angiogenesis and osteogenesis in rabbit femoral head osteonecrosis. Bone. 2015;81:544-53.

40. Srinivasan S, Chitalia V, Meyer RD, Hartsough E, Mehta M, Harrold I, et al. Hypoxia-induced expression of phosducin-like 3 regulates expression of VEGFR-2 and promotes angiogenesis. Angiogenesis. 2015;18:449-62.

41. Rey S, Luo W, Shimoda LA, Semenza GL. Metabolic reprogramming by HIF-1 promotes the survival of bone marrow-derived angiogenic cells in ischemic tissue. Blood. 2011;117:4988-98.

\section{Ready to submit your research? Choose BMC and benefit from:}

- fast, convenient online submission

- thorough peer review by experienced researchers in your field

- rapid publication on acceptance

- support for research data, including large and complex data types

- gold Open Access which fosters wider collaboration and increased citations

- maximum visibility for your research: over $100 \mathrm{M}$ website views per year

At BMC, research is always in progress.

Learn more biomedcentral.com/submissions 